\title{
Energy quay walls
}

\author{
Jacco Haasnoot ${ }^{1, *}$, Philip J. Vardon ${ }^{2}$, Ivaylo Pantev ${ }^{2}$, Silvia Bersan ${ }^{1}$, Bob Bloemers $^{3}$ and David Smeulders ${ }^{4}$ \\ ${ }^{1}$ CRUX Engineering BV, Pedro de Medinalaan 3c, 1086 XK Amsterdam, the Netherlands \\ ${ }^{2}$ Delft University of Technology, Section of Geo-Engineering, PO Box 5048, 2600GA Delft, the Netherlands \\ ${ }^{3}$ Groep Duurzame Energie BV, Waalbandijk 1, 4053 JB IJzendoorn, the Netherlands \\ ${ }^{4}$ Eindhoven University of Technology, Faculty of Mechanical Engineering - Energy Technology, PO Box 513 , 5600 MB Eindhoven, the \\ Netherlands
}

\begin{abstract}
In the Netherlands and other countries around the world there are extensive canals and rivers with banks supported by walls. Especially in the historic inner cities of the Netherlands, quay walls currently need to be replaced. During construction, temporary valuable underground space is created that can be used to accommodate energy installations for the benefit of the surrounding buildings. The quay wall itself can also be a thermal active structure relying on a combination of aquatic and geothermal energy. Two different designs for quay walls incorporating thermal energy infrastructure have been designed: (i) based around a sheet pile; and (ii) based around a concrete pile with a ' $\mathrm{L}$ ' wall on top. An evaluation of the energy, mechanics, finances and $\mathrm{CO}_{2}$ saving is presented for a case study in this paper. It is seen that for the case studies elaborated, both walls can supply sufficient thermal energy for the houses along the canals improved by good use of surface water, reduce $\mathrm{CO}_{2}$ emissions by more than 1 tonne per meter length and can be financially positive. The influence on the mechanical performance of the energy quay wall (settlements, bearing capacity and bending) has been evaluated and found to be reassuringly small.
\end{abstract}

\section{Introduction}

In the Netherlands and other countries around the world there are extensive canals and rivers with banks supported by walls. Especially in the historic inner cities of the Netherlands, quay walls need to be replaced. During construction temporary valuable underground space is created that can be used to accommodate energy installations for the benefit of the surrounding buildings. The quay wall itself can also be a thermal active structure relying on a combination of aquatic and geothermal energy.

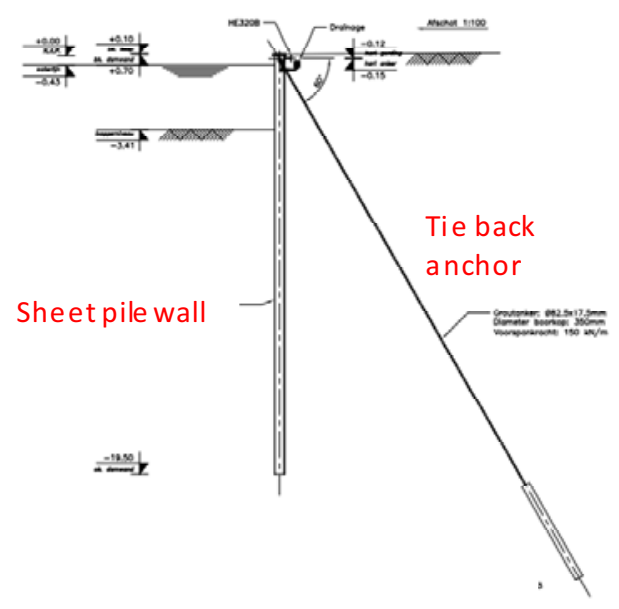

Fig. 1. Quay wall, sheet pile wall.

\footnotetext{
* Corresponding author: $\underline{\text { Haasnoot } @ \text {,cruxbv.nl }}$
}

\section{Quay walls in the Netherlands}

Two different designs for quay walls incorporating thermal energy infrastructure have been designed: (i) based around sheet piles (Fig.1.) and (ii) based around concrete piles with a 'L' wall on top (Fig.2.).

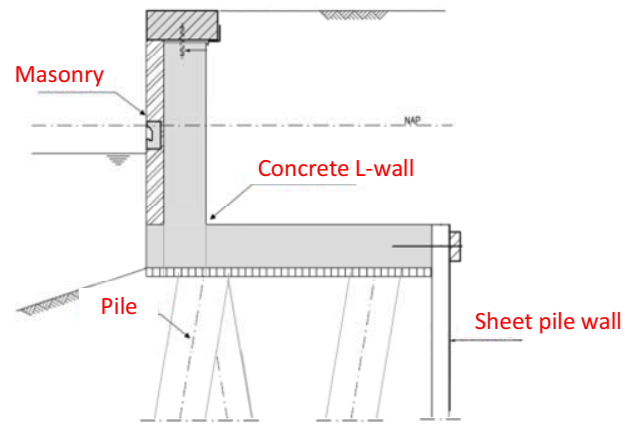

Fig. 2. Quay wall, L-wall on piles.

The L-wall on piles is a type of quay that is commonly used to renovate the existing quay wall in historic inner cities such as Amsterdam. The city of Amsterdam will have to renovate the existing stretch of $200 \mathrm{~km}$ of quay walls in the coming decade. By thermally activating the L-wall and the piles, it has the potential to play an important role in the energy transition of the Netherlands and contribute to fulfilling the national $\mathrm{CO}_{2}$ reduction goals. 
Sheet pile walls are also applied in inner cities, but more abundantly along the larger canals and rivers throughout the country. Sheet pile walls can be thermally activated as shown in [1]. Sheet pile walls are often used in underground construction and as a quay wall and have a huge potential as a heat exchanger providing sustainable energy for nearby buildings.

\section{Potential}

\subsection{Definition Potential}

Following the approach of [2], we make a distinction between theoretical, technical, economic and market potentials. In this analysis we initially confine ourselves to the theoretical potential that comprises the maximum amount of energy that can theoretically be generated without taking account of technical and societal constraints such as conversion losses, maintenance and safety. Competition with other uses such as exclusion of nature reserves and distance restrictions are included in this potential, as well as obvious limitations such as, for example, maximum acceptable cooling of surface waters by heat extraction.

Usable heat is extracted in summer when the surface water is sufficiently warm. In summer, however, there is often no demand for space heating for homes or nonresidential buildings. The heat extracted must therefore be stored until the demand for heat increases again in autumn or winter. For this purpose, a link with ground storage systems is obvious (heat and cold storage systems, thermally active sheet pile wall). Storage will inevitably involve losses, so the technical potential of surface water will be lower than the theoretical potential. These losses are generally known and can be reduced by system optimisation. Within the economic potential a trade-off is made from the investor's perspective where the cost-effectiveness of the technology is decisive. Finally, the market potential is that part of the economic potential that is expected to be realised under current legislation and regulations, possibly with the help of existing subsidy schemes.

\subsection{Theoretical Potential canals and rivers}

The amount of heat that can be extracted from waterways under given conditions is the so-called heat extraction capacity (WOC). This is expressed in $\mathrm{J} / \mathrm{s}$ (Watt). The main component depends on the flow rate $Q$ $\left[\mathrm{m}^{3} / \mathrm{s}\right]$ of the waterway, the temperature reduction of the water $T\left[{ }^{\circ} \mathrm{C}\right]$, and the volumetric heat capacity of the water $c\left[\mathrm{~J} / \mathrm{m}^{3} /{ }^{\circ} \mathrm{C}\right]$ :

$$
W O C Q=Q \times T \times c
$$

For example, the Rhine river at Lobith entering the Netherlands has a flow of $2000 \mathrm{~m}^{3} / \mathrm{s}$, this could create an $8.4 \mathrm{GW}$ thermal power station with only $1^{\circ} \mathrm{C}$ cooling of the water. This is more than a quarter of the total installed electrical power in the Netherlands and outlines the enormous theoretical potential of the waterways in the Netherlands. However, it would also mean that no heat can be extracted from stagnant waters ( $Q$ is zero). This is unrealistic because water surfaces (both flowing and stationary) are also directly heated by the air (assuming that the temperature of the air is higher than that of the water) and radiation. There is therefore an additional heat extraction capacity WOCopp:

$$
\text { WOCopp }=h \times A \times T
$$

where $h$ is the heat transfer coefficient $\left[\mathrm{W} / \mathrm{m}^{2} /{ }^{\circ} \mathrm{C}\right]$, and $A$ is the water surface. WOC is then the sum of WOCQ and WOCopp. On the basis of the above formulas, Deltares and Stowa have made a distribution of the total heat extraction capacity for each calculation element of the National Water Model (stowa.omgevingswarmte.nl) based on the assumptions that

(i) heat cannot be extracted until the surface water temperature exceeds $15^{\circ} \mathrm{C}$;

(ii) the water must not be cooled further than $12^{\circ} \mathrm{C}$; and

(iii) the water must not be cooled by more than $6^{\circ} \mathrm{C}$. For example, if the water is $19^{\circ} \mathrm{C}$, it may only be cooled to $13^{\circ} \mathrm{C}$.

\section{Thermal Active Sheet Pile wall}

\subsection{Introduction}

The technical feasibility of an energy sheet pile wall is determined by its ability to generate and/or store energy. In order to understand the system properly and thus to be able to design it effectively in the future, a COMSOL $\AA$ calculation model has been set up and various scenarios have been calculated. This paper summarises the main findings of these simulations.

\subsection{System description}

The energy sheet pile wall consists of an incoming and outgoing pipe that can be installed on the soil side of any sheet pile wall. In the case of new sheet piling, this can be installed at the same time as the sheet piling is inserted. In the case of existing sheet piling, it is possible to install it retrospectively using a technique similar to the installation of tie back anchors. These pipes form a soil / water heat exchanger that can supply heat (or cold through passive cooling) to homes via a heat pump. The heat exchange with the environment then takes place over two different areas, one in contact with the canal water (free convection) and one below the base of the canal, in contact with the ground. The flow in the waterway provides convection that makes an important contribution to the efficiency of heat exchange between the heat exchanger and the water mass. 


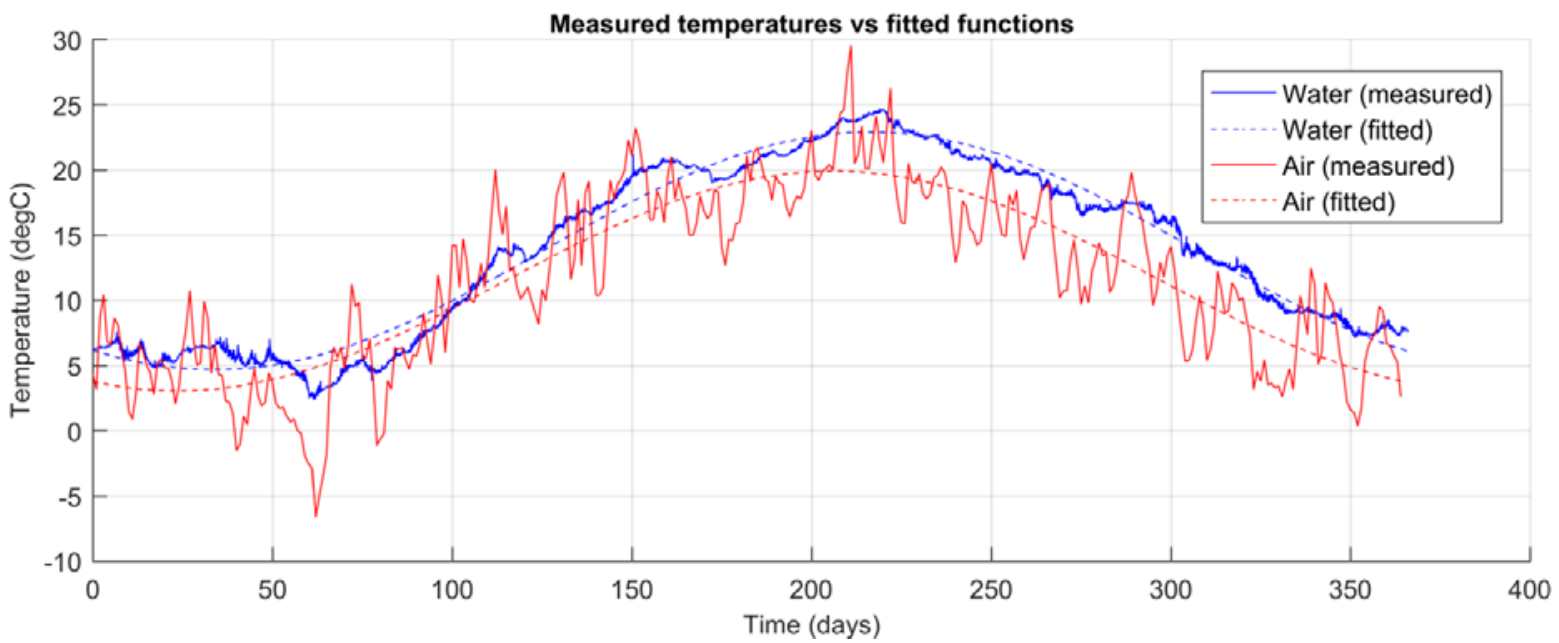

Fig 3. Water (NDSM Amsterdam) and air (Schiphol) measured and fitted temperature fluctuations in 2018

\subsection{Temperature data}

Temperature measurements for canal water, ambient air and ground temperature are important for the reliability of numerical model results. These were not available for the exact area of interest, hence measurements that were recorded as close together as possible were used. The water temperature measurements collected at the NDSM Amsterdam (located in the IJ river) were available via the Rijkswaterstraat and were therefore used in the analysis. It is important to note that these are not direct measurements of the temperature in the waterways. The air temperatures recorded every 6 hours originate from the weather station at Schiphol Airport.

The measurements in Figure 3 show that the water temperature shows considerably less short-term fluctuations than the air. In addition, the average water temperature is generally higher than the average air temperature. The fitted sinusoidal trends (shown in Figure 3) are used in the analysis. Short-term temperature fluctuations can be critical to the peak power of the system, therefore they should be investigated at a detailed design stage. An additional requirement is a suitable model (for the design space and buildings) for predicting the heat demand based on the ambient temperature.

The soil temperature in the shallow subsoil is affected by fluctuations in the ambient air temperature. Measurements carried out using a thermal CPT test in 2018 have shown a relatively constant temperature below a depth of approx. $12 \mathrm{~m}$, but local temperature measurements are necessary to quantify this for the study areas. The analyses presented here take into account the additional influence of a water body (channel) on the variation in soil temperature.

\subsection{Numerical modelling}

Initial heat exchange models using COMSOL Multiphysics ${ }^{\circledR}$ have been carried out to estimate the heat exchange potential of the scenarios drawn up. An important question to be answered in the feasibility study concerns the achievable potential for heat extraction from water and soil for the different design solutions. Therefore, the preferred option is to capture the forced convection in the heating pipes. The COMSOL module "Heat exchange in pipes" was used for this purpose. The heat pipes are thus explicitly modelled in the model. The distance between the inlet and outlet pipes is $0.3 \mathrm{~m}$, which is a common size for standard sheet piling. An impression of the model is given in Figure 4. Water in the waterway is mixed well (i.e. uniform temperature). This assumption is correct if there is sufficient flow. In essence, the waterway functions as a heat source with an infinite capacity.
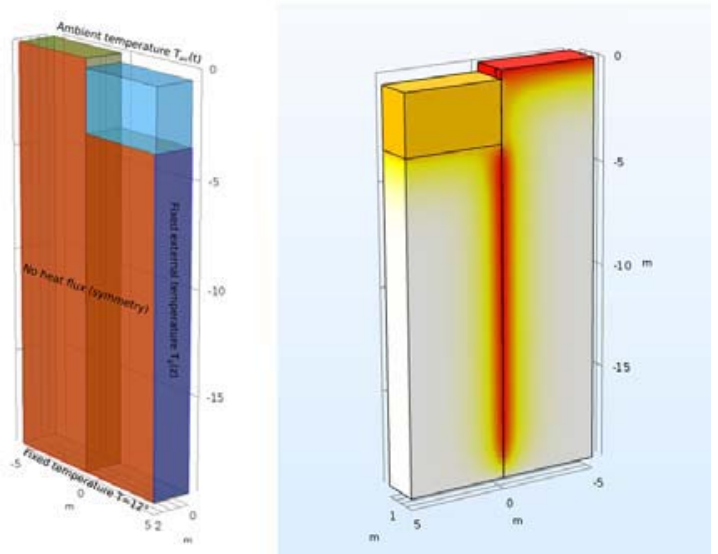

Fig 4. Impression of the calculation model

\subsection{Scenarios}

Two scenarios have been defined for the evaluation of the heat exchange potential. These include different modes of operation of the heat exchanger system and are shown in Table 1. Scenario A can be considered as the worst case solution, extracting heat from the subsurface and leaving recovery to natural processes. This may lead to a further reduction in energy yield. Scenario B, on the other hand, considers the "best solution", where the heat 
extracted is actively recovered during the summer period from the canal water.

Table 1. Scenario's.

\begin{tabular}{|c|c|c|}
\hline Scenario & Period & Conditions \\
\hline \multirow{3}{*}{$\begin{array}{c}\text { Scenario } \\
\text { A }\end{array}$} & $\begin{array}{c}15 \text { Nov }- \\
15 \mathrm{Mar}\end{array}$ & Heat extraction from the soil \\
\cline { 2 - 3 } & $\begin{array}{c}15 \mathrm{Mar}- \\
15 \mathrm{Nov}\end{array}$ & $\begin{array}{c}\text { Natural recovery (no flow in } \\
\text { heat exchangers tubes) }\end{array}$ \\
\hline \multirow{3}{*}{$\begin{array}{c}\text { Scenario } \\
\text { B }\end{array}$} & $\begin{array}{c}15 \mathrm{Nov}- \\
15 \mathrm{Mar}\end{array}$ & Heat extraction from the soil \\
\cline { 2 - 3 } & $\begin{array}{c}15 \mathrm{Mar}- \\
15 \mathrm{Nov}\end{array}$ & $\begin{array}{c}\text { Recovery through heat } \\
\text { extraction from the canal }\end{array}$ \\
\hline
\end{tabular}

\subsection{Results}

As can be expected, Scenario A leads to an exhaustion of the soil heat (i.e. annual lowering of temperature) due to constant heat extraction during the heating season. In order to design a sustainable system, a possibility of forced recovery must be possible by means of heat supply and storage.

Scenario B looks at pumping the fluid through the heat exchangers in the out-of-season period in order to use the canal temperature to recover the temperature in the subsurface. The soil temperature can recover above the initial level, indicating energy storage (Figure 5). In a detailed design situation, the peak demand needs to be further investigated, requiring a short term model to cope with daily fluctuations in air, soil and water temperature.

\section{L-wall on Energy Piles}

The example L-wall solution includes three rows of raking piles. The middle row rakes in the opposite direction, away from the canal. In the example piles are inclined at a ratio of 5:1 (Figure 6). A model including all the piles along one side of the canal was not deemed feasible to execute, hence a unit of symmetry was defined. This includes two piles of from the extreme rows as well as two halves of middle-row piles. The pattern is repeated along the length of the canal. Furthermore, all tubes are connected together to form a single loop and maximise the active length for heat exchange.

A pile length of $19 \mathrm{~m}$ was considered, with two Utubes per pile and a shank spacing of $0.12 \mathrm{~m}$. It should be noted that the number of tubes per pile can be altered depending on the diameter of the piles. Two U-tubes were considered appropriate for piles with diameter 0.3 $0.4 \mathrm{~m}$. The pattern is repeated along the length of the canal. Furthermore, all tubes in the model were connected together to form a single loop and maximise the active length for heat exchange. The scenario's as described in Table 1 were also calculated for the L-wall on energy piles.

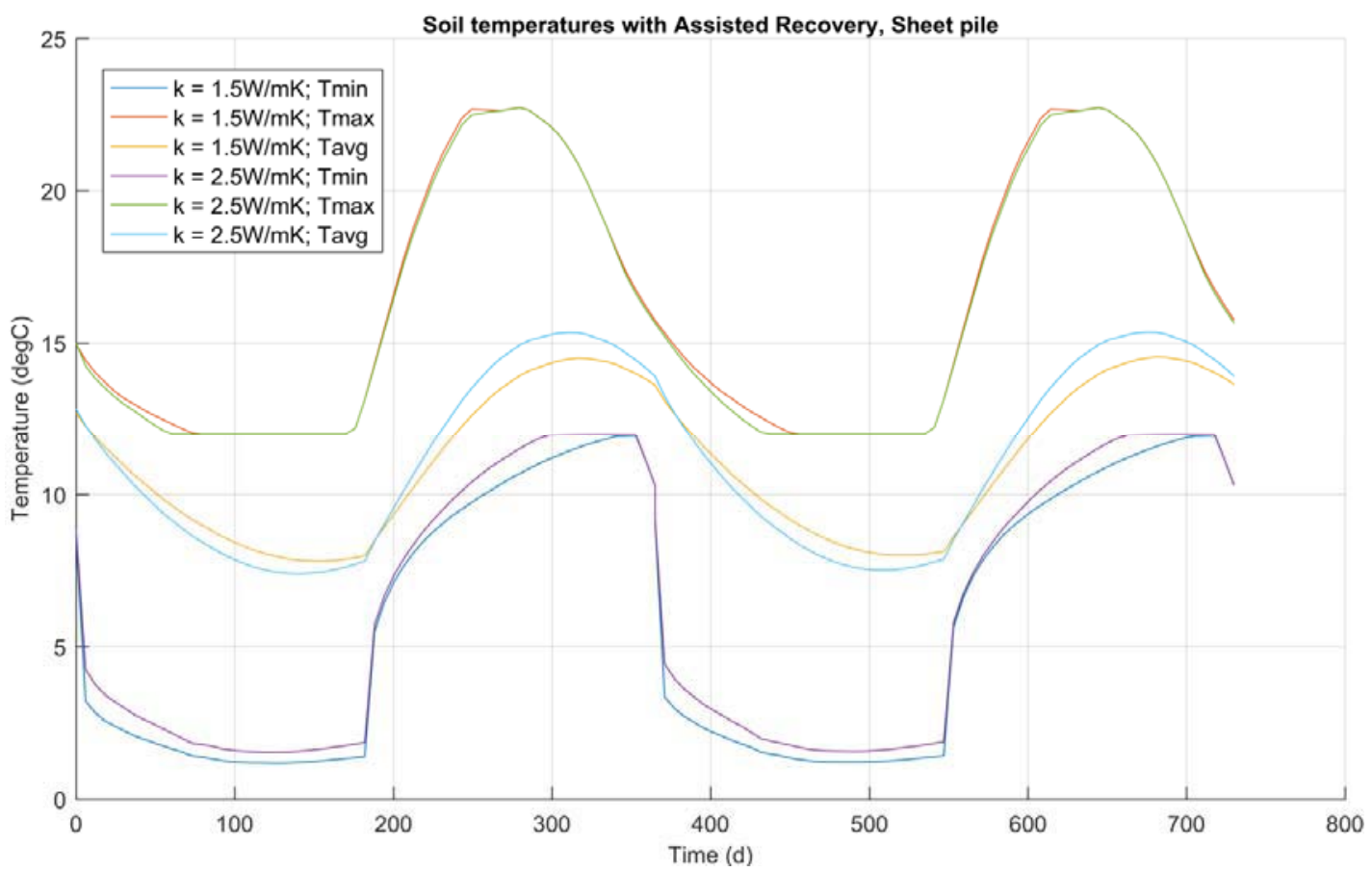

Fig 5. Soil temperature for an energy sheet pile wall in Scenario B for the period of 2 years 

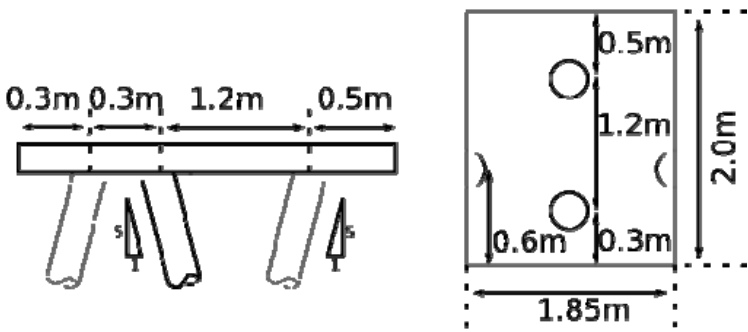

Fig 6. Unit of symmetry for the Comsol Model.

\section{Performance}

The calculations show that amount of annual energy that can be delivered by both systems is in the order of $2000 \mathrm{kWh} / \mathrm{m}$ (running meter quay wall). The calculations show that for the calculated cases the sheet pile wall performs about $10 \%$ better than the L-wall on energy piles. It should be noted that the performance of the heating (or cooling) systems often is governed by the power of the heating system for the extreme heating or cooling periods throughout the year.

\section{Geotechnical Risks}

\subsection{Mechanism}

The geotechnical risks are considered to be low and can be attributed to the following mechanisms:

(i) thermal expansion or contraction of the soil; and

(ii) thermal expansion or contraction of the pile or sheet pile.

Both the soil and the pile expand when heated and contract when cooled. The expansion and contraction is cyclic: the soil expands in summer and contracts in winter. In the upper meters of soil, this already occurs naturally in response to variations in outside temperature and canal temperature. The heat exchanger will also introduce this phenomenon into the deeper soil layers. While short term thermal changes will occur, the majority of the heat exchange is annual and therefore this is the dominant cycle.

Shrinkage of the soil can be elastic (recoverable) or plastic, the latter case is called thermal consolidation. Thermal consolidation will typically occur in soft, unconsolidated soils or at low soil stresses (shallow soil layers). Thermal consolidation occurs when the temperature varies relatively quickly. Therefore, the mechanism will only be able to act in a limited area around the pile/ sheet pile wall. Through consolidation, the soil becomes denser and stronger and deformations decrease over time. In the case of pile foundations, the heat exchanger is embedded in the concrete. The temperature in the soil then varies less quickly and thermal consolidation is less likely.

\subsection{Effects of settlement/heave}

If the soil next to the piles settles more than the sheet piles themselves, negative skin friction develops, which then leads to limited settlement of the structural element. Modern piles and sheet pile constructions are designed in such a way that there is sufficient bearing capacity to absorb the negative skin friction, even when the sheet pile itself must be able to take a vertical load from the superstructure or anchoring. Thermal expansion and shrinkage of the sheet pile wall/pile itself is elastic. In tests it has been observed that cyclic thermal deformations, due to interaction with the soil, lead to settlements in pile foundations that accumulate over the years (ratcheting). This occurs in particular when piles are loaded vertically by a high load close to the loadbearing capacity. It is expected that new piles designed in accordance with the Eurocode will have a sufficient margin between the load and bearing capacity. Settling of the soil behind a sheet pile wall and of the sheet pile wall itself can lead to (limited) subsidence of the ground level behind the sheet pile wall, as is currently the case due to deflection of the sheet pile wall. Initial calculations show that the contribution of the thermal activation of the sheet pile wall on this settling will be within the bandwidth of common ground level settlements. Thermal expansion of the sheet piling is prevented at the tip. This can cause slight bending within the steel profile. However, the extent of the temperature variation falls within the values of a normal quay construction.

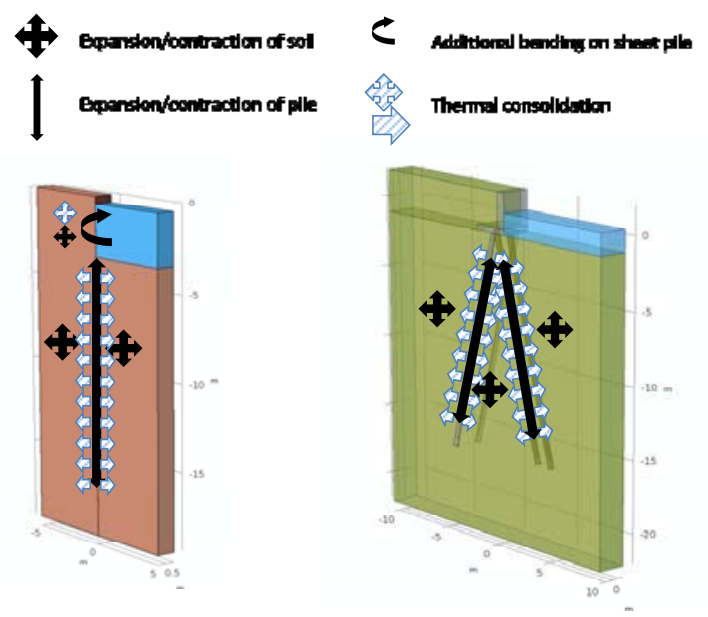

Fig 7. Diagram of two types of energy quay walls with indication of the thermal - hydro - mechanical processes that can have a positive or negative influence on the construction, left the energy quay wall, right the energy quay wall

\subsection{Effects of deformation in the horizontal direction}

Expansion or contraction of the soil next to a sheet pile wall can also lead to a variation in the active and passive soil pressure. This can - theoretically - lead to an increase in the bending moment and a reduction in stability. In the lower part of the sheet pile wall the soil 
deformations will be symmetrical so that no adverse effect is to be expected. Because in the upper part the soil is only present on one side, an increase of the bending moment is expected. This is usually also the zone where in the current (natural) situation a temperature variation in the soil occurs. This extra moment, if the temperature variation is more than occurs naturally than at present, must be included in the sheet piling design.

Figure 7 gives an overview of the geotechnical mechanisms that are important for a thermally active sheet pile wall or pile foundation.

\section{Economic Feasibility}

In order to determine the economic feasibility of the thermally active sheet pile wall, a fictitious building in Delft alongside the canal is taken as a illustrative case. The following characteristics have been given to the building:

- residential function

- 100 apartments with an average GLA of $80 \mathrm{~m}^{2} /$ apartment

- Total GLA therefore amounts to $8000 \mathrm{~m}^{2}$

- Heat demand per $\mathrm{m}^{2}: 0.15 \mathrm{GJ} / \mathrm{m}^{2}$

- Domestic hot water demand per $\mathrm{m}^{2}: 0.139 \mathrm{GJ} / \mathrm{m}^{2}$

- Cooling demand per $\mathrm{m}^{2}: 0.05 \mathrm{GJ} / \mathrm{m}^{2}$

The technical concept consists of thermally active sheet pile walls that can extract the energy from the adjacent surface water. A heat pump is used so that the energy generated is upgraded to higher temperatures. In the calculations below an average efficiency (COP) of the system of 3.6 has been taken into account.

On an annual basis, the following energy demand is supplied:

$\begin{array}{ll}\text { heating: } & 1200 \mathrm{GJ} \\ \text { hot tap water: } & 1112 \mathrm{GJ} \\ \text { cooling: } & 400 \mathrm{GJ}\end{array}$

From the energy demand it can be calculated what the energy quantity from the thermally active sheet pile wall should be. This will correspond to approx. 290 MWh per year. For this approximately 150 metres of thermally active sheet piling is required. For an L-wall on energy piles the total length would be somewhat larger, in the order of $170 \mathrm{~m}$.

The annual $\mathrm{CO}_{2}$ reduction for this case is 183 tonnes $\mathrm{CO}_{2}$ for a quay wall length of 150 to $170 \mathrm{~m}$. The reduction of annual $\mathrm{CO}_{2}$ exhaust is therefore 1.1 to 1.2 tonne of $\mathrm{CO}_{2}$ per running meter of quay wall.

By means of the projected consumptions and revenues, a business case has been drawn up with regard to the financial feasibility. From the business case a financial feasibility can be derived that a acceptable additional investment remains compared to a conventional energy supply for an Energy Service Company to be able to operate the system in a financially profitable manner. The IRR is determined at approximately 8 years given the present regulation in the Netherlands.
From this analysis it is concluded that the application of an energy quay wall for the case considered is very promising and financially sound.

\section{Conclusions}

On the basis of the technical and financial analyses presented in this paper, the following conclusions can be drawn.

It is concluded that the energy quay wall is a feasible concept. The advanced numerical simulations performed with time-dependent models that cover all important aspects of the energy system, show that heat does not "leak away" significantly due to the presence of a (well heat-conducting) steel sheet piling, but even makes a somewhat positive contribution. In addition, the analysis showed that the geotechnical risks to the primary function of the sheet piling are minimal and that the business case is positive.

Further case studies are performed to apply the energy quay wall as an energy factory in the inner city of Amsterdam. South of Delft in the Netherlands, a full scale trial will be performed in 2020 with an energy sheet pile wall to verify the thermal and geotechnical performance of the energy sheet pile wall (Figure 8). This test will be executed in close cooperation with Gooimeer B.V. and is partly funded by the Netherlands Enterprise Agency and the province of Zuid-Holland.

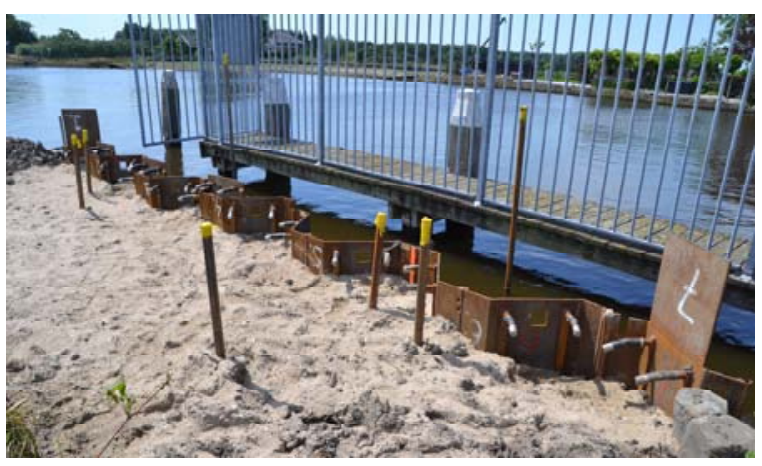

Fig 8. Test set-up of the energy sheet pile wall near Delft, the Netherlands

\section{References}

1. M. Ziegler, D. Koppmann, R. Pechnig, D. Knapp, Energy sheet pile walls - Experimental and numerical investigation of innovative energy geostructures, Conf. Proc. XVII European Conference on Soil Mechanics and Geotechnical Engineering-Reykjavík, Iceland (2019)

2. CE Delft, Deltares, 'National potential of aquathermal energy', in Dutch (2018) 